\title{
Prolonged Central $\mu$-Opioid Receptor Occupancy after Single and Repeated Nalmefene Dosing
}

\author{
Kimmo Ingman 1,4, Nora Hagelberg ${ }^{2,5}$, Sargo Aalto², Kjell Någren ${ }^{2}$, Auni Juhakoski ${ }^{3}$, Sakari Karhuvaara $^{3}$, \\ Antero Kallio $^{3}$, Vesa Oikonen ${ }^{2}$, Jarmo Hietala ${ }^{2,6}$ and Harry Scheinin ${ }^{*, 2,4}$ \\ 'Clinical Research Services Turku (CRST), University of Turku, Turku, Finland; ${ }^{2}$ Turku PET Centre, University of Turku, Turku, Finland; ${ }^{3}$ Biotie \\ Therapies Corp., Turku, Finland; ${ }^{4}$ Department of Pharmacology and Clinical Pharmacology, University of Turku, Turku, Finland; ${ }^{5}$ Department of \\ Anaesthesiology and Intensive Care, Turku University Central Hospital and University of Turku, Turku, Finland; 'Department of Psychiatry, \\ University of Turku, Turku, Finland
}

\begin{abstract}
The opioid antagonist nalmefene offers an alternative to traditional pharmacological treatments for alcoholism. The present study was designed to investigate the relationship between nalmefene plasma concentration and central $\mu$-opioid receptor occupancy after a clinically effective dose (20 mg, orally). Pharmacokinetics and $\mu$-opioid receptor occupancy of nalmefene after single and repeated dosing over 7 days was studied in 12 healthy subjects. Serial blood samples were obtained after both dosings, and pharmacokinetic parameters for nalmefene and main metabolites were determined. Central $\mu$-opioid receptor occupancy of nalmefene was measured with positron emission tomography (PET) and [ ' $\mathrm{C}$ ]carfentanil at four time points $(3,26,50,74 \mathrm{~h})$ after both dosings. Nalmefene was rapidly absorbed in all subjects. The mean $t_{1 / 2}$ of nalmefene was $13.4 \mathrm{~h}$ after single and repeated dosing. The accumulation of nalmefene and its main metabolites in plasma during the repeated dosing period was as expected for a drug with linear pharmacokinetics, and steady-state was reached for all analytes. Both nalmefene dosings resulted in a very high occupancy at $\mu$-opioid receptors (87-100\%), and the decline in the occupancy was similar after both dosings but clearly slower than the decline in the plasma concentration of nalmefene or metabolites. High nalmefene occupancy (83-100\%) persisted at $26 \mathrm{~h}$ after the dosings. The prolonged $\mu$-opioid receptor occupancy by nalmefene indicates slow dissociation of the drug from $\mu$-opioid receptors. These results support the rational of administering nalmefene when needed before alcohol drinking, and they additionally suggest that a high $\mu$-opioid receptor occupancy can be maintained when nalmefene is taken once daily.

Neuropsychopharmacology (2005) 30, 2245-2253. doi:I 0.1038/sj.npp. I 300790; published online 8 June 2005
\end{abstract}

Keywords: $\mu$-opioid receptor; opioid antagonists; alcoholism; nalmefene

\section{INTRODUCTION}

Nalmefene is an opioid receptor antagonist that has been suggested to have several applications in the treatment of dependence disorders, including alcoholism (Mason et al, 1999). The current guidelines for the pharmacotherapy of alcohol dependence with opioid antagonist recommends daily use of naltrexone alongside nonpharmacological interventions (Balldin et al, 2003; O'Malley et al, 2003; O'Malley, 1995; Srisurapanont and Jarusuraisin, 2002). However, the treatment regimen has failed to reduce alcohol drinking in several studies (Gastpar et al, 2002; Krystal et al, 2001) and patients treated with naltrexone have experienced adverse effects that have

\footnotetext{
* Correspondence: Professor H Scheinin, Turku PET Centre, University of Turku, PO Box 52, FIN-2052I Turku, Finland. Tel: + 3582313 |870, Fax: + 3582 231 8191, E-mail: harry.scheinin@utu.fi

Received 30 December 2004; revised and accepted 29 April 2005 Online publication: 3 May 2005 at http://www.acnp.org/citations/ Npp0503050406 / 6/default.pdf
}

led to poor medication compliance and impaired treatment outcome (Kranzler et al, 2000; Oncken et al, 2001).

Nalmefene has been proposed to offer an advantage over naltrexone in the treatment of alcoholism (Mason et al, 1999). Nalmefene is a more potent antagonist at $\delta$-opioid receptors (DeHaven-Hudkins et al, 1990; Emmerson et al, 1994) that have been implicated in alcohol drinking (Ciccocioppo et al, 2002; June et al, 2004), and the plasma terminal half-life of oral nalmefene (Dixon et al, 1987; Gal et al, 1986) markedly exceeds that of naltrexone (Meyer et al, 1984). Single oral nalmefene doses of $20-300 \mathrm{mg}$ and repeated doses of $10-40 \mathrm{mg}$ twice a day have been well tolerated (Dixon et al, 1987; Mason et al, 1994), and there have been no reports of any serious adverse drug reactions on hepatic or other body systems.

Nalmefene reduces alcohol drinking in preclinical models (June et al, 1998; June et al, 2004). Recent findings indicate that nalmefene and naltrexone are equally effective in reducing subjective responses to alcohol in alcoholics (Drobes et al, 2004), and in clinical studies, nalmefene has 
been associated with significant decreases $v s$ placebo in reducing relapse to heavy drinking (Mason et al, 1994; Mason et al, 1999). Nevertheless, in a recent multicenter trial in which nalmefene was used in combination with Motivational Enhancement Therapy, there was no statistically significant difference $v s$ placebo in the reduction of heavy drinking (Anton et al, 2004). A more extensive clinical program is currently ongoing in which the safety and efficacy of targeted nalmefene in reducing heavy alcohol drinking is assessed.

The present study was undertaken to determine and compare the pharmacokinetic characteristics of a clinically relevant nalmefene dose $(20 \mathrm{mg})$ after single and 7 -day repeated oral dosing. Positron emission tomography (PET) imaging studies with $\left[{ }^{11} \mathrm{C}\right]$ carfentanil were performed at several time points (3-74 h) after both dosings to estimate the time course of central $\mu$-opioid receptor occupancy by nalmefene.

\section{MATERIALS AND METHODS}

\section{Subjects}

A total of 12 healthy male subjects (mean age $=23.3$ years, range: 18-29 years) were enrolled for the study. Each subject was given a complete description of the study before written informed consent was obtained. All subjects were in good health as determined by medical history, laboratory tests, and physical examination. No history of substance abuse was allowed, and only subjects who were not on any regular medication were considered eligible for the study. The study protocol was approved by the Ethical Committee of Hospital District of Varsinais-Suomi, and the study was performed in accordance with the Declaration of Helsinki (World Medical Association Declaration of Helsinki, 2000) and guidelines for Good Clinical Practice (Committee for Proprietary Medicinal Products and International Conference on Harmonisation, 1995).

\section{Study Outline}

The study design was open-label, and nonrandomized with two periods. Single nalmefene $\mathrm{HCl}(20 \mathrm{mg}$, orally) administration was studied first, followed by repeated dosing (20 mg orally, once daily over 7 days) after a drug-free wash-out period of at least 1 week, and no more than 1 month. Tablets were always taken at the same time in the morning, and subjects fasted for at least $4 \mathrm{~h}$ before and $2 \mathrm{~h}$ after tablet ingestion. Blood samples for pharmacokinetic analyses were collected immediately before the single dose and the last dose of repeated dosing (day 7 ), and at $0.25,0.5$, $1,2,3,4,6,8,10,12,16,24,48$, and $72 \mathrm{~h}$ after the doses. In addition, trough samples were collected on days 1-6 during the repeated dosing period. Eight subjects participated in PET studies, and they were scanned before nalmefene administration in order to obtain quantitative baseline data of $\mu$-opioid receptor distribution. Thereafter, the subjects were assigned for PET imaging at 3, 26, 50, or $74 \mathrm{~h}$ after single nalmefene administration so that two subjects were scanned at each time point. Similar arrangements, with the same two subjects scanned at each time point, were made after the last dose of repeated dosing (day 7), except for only one scanning that was performed at $50 \mathrm{~h}$ due to a technical problem. Twelve lead ECG was obtained at screening, and before and at $3 \mathrm{~h}$ after nalmefene intake on the single dose day and the last treatment day (day 7) of repeated dosing. Safety and tolerability monitoring was performed throughout the study.

\section{Pharmacokinetic Assessments}

Blood samples were collected through an indwelling plastic cannula, inserted into a superficial upper arm vein, into tubes containing anticoagulant Li-heparin. They were drawn at given time points, centrifuged, and plasma was separated within $1 \mathrm{~h}$ of sampling. The plasma specimens were frozen at $-20^{\circ} \mathrm{C}$ or colder until analyzed. Nalmefene, nornalmefene, and the internal standard (naltrexone) were extracted from plasma with ethyl acetate. The organic layer was transferred to clean tubes and evaporated to dryness. The residue was reconstituted in mobile phase and aliquots were injected into a high-pressure liquid chromatographymass spectrometry (1100 LC-MS-system, Agilent Technologies Waldbronn, Germany) system. Two analyses were made of each study sample: determination of intact (nonconjugated) nalmefene and nornalmefene, and determination of total concentration of the analytes. A set of plasma standards containing $0.25-40 \mathrm{ng} / \mathrm{ml}$ of nalmefene and nornalmefene in drug-free plasma was used to construct a calibration curve for each batch of plasma samples. Four quality control samples containing 0.40, 1.60, 8.00 , and $24.0 \mathrm{ng} / \mathrm{ml}$ of nalmefene and nornalmefene were analyzed in duplicate in each batch of study samples. The interbatch precision (CV\%) for nalmefene was from 4.3 to $7.3 \%$ and for nornalmefene from 4.3 to $10.8 \%(n=12)$. The determination of total concentration of the analytes in study samples required enzymatic hydrolyzes of the glucuronide conjugates ( $\beta$-Glucuronidase, Sigma G1512), and total concentration was analyzed with calibration range from 1.25 to $200 \mathrm{ng} / \mathrm{ml}$. Two spiked and two pooled control samples were analyzed in duplicate in each sample batch. The spiked control samples $(8.0$ and $80 \mathrm{ng} / \mathrm{ml})$ were made by spiking drug-free plasma with nalmefene and nornalmefene solutions to contain known concentrations of the analytes. The pooled controls were made by pooling plasma of previously analyzed study samples. Concentrations of nalmefene in plasma pools were 28.1 and $104 \mathrm{ng} / \mathrm{ml}$ and concentrations of nornalmefene 5.65 and $13.8 \mathrm{ng} / \mathrm{ml}$, respectively. The spiked plasma controls indicated stability of intact analytes under analytical conditions, including the hydrolysis. The pooled control samples demonstrated especially the repeatability of the enzymatic hydrolyzes. The interbatch precision (CV\%) was from 2.8 to $6.8 \%$ for nalmefene and from 4.7 to $10.3 \%$ for nornalmefene. After the total concentrations and concentrations of intact compounds were analyzed, the concentrations of the respective glucuronidated compounds were calculated by subtraction.

Pharmacokinetic variables of nalmefene, nornalmefene, nalmefene glucuronide, and nornalmefene glucuronide were determined from the concentration-time data by the PCNONLIN software (Version 4.2; Pharsight Corporation, Mountain View, CA, USA) using noncompartmental methods. Peak concentration $\left(C_{\max }\right)$, taken as the maximum 
observed concentration in plasma, and time to peak concentration $\left(t_{\max }\right)$ were observed. After a single dose of nalmefene, area under the plasma concentration-time curve from time zero to infinity $\left(\mathrm{AUC}_{\infty}\right)$ was calculated by the trapezoidal rule to the last observed concentration with extrapolation to infinity by dividing the last observed concentration by the elimination rate constant. After the last dose of repeated dosing (day 7), area under the plasma concentration-time curve from time zero to $24 \mathrm{~h}$ (i.e. AUC of the dosing interval $\left(\mathrm{AUC}_{\tau}\right)$ ) was calculated by the trapezoidal rule. Terminal half-life $\left(t_{1 / 2}\right)$ was calculated by ln 2/elimination rate constant, which was determined by unweighted linear least-squares regression analysis from the linear segment of the log-transformed concentration-time data. The effect of minor deviations from the planned blood sampling times in the pharmacokinetic analysis was cancelled out by using actual sampling times in calculations.

\section{PET Assessments}

$\left[{ }^{11} \mathrm{C}\right]$ Carfentanil was obtained from a reaction of high specific radioactivity $\left[{ }^{11} \mathrm{C}\right]$ methyl triflate, prepared from $\left[{ }^{1} \mathrm{C}\right]$ methane, and desmethyl carfentanil (ABX advanced biochemical compounds, Radeberg, Germany). After purification of the reaction product by HPLC, the purified fraction was evaporated, and the product was formulated in a sterile solution and filtered through a sterile filter into a sterile vial. PET studies were performed at Turku PET Centre using a GE Advance scanner (General Electrics Medical Systems, Milwaukee, WI, USA). An intravenous bolus of approximately $250 \mathrm{MBq}$ (mean mass $=0.77 \mu \mathrm{g}$ ) of $\left[{ }^{11} \mathrm{C}\right]$ carfentanil was manually administered in each subject, followed by a $69 \mathrm{~min}$ dynamic 3D (septa retracted) tissue activity image acquisition (consisting of three $1 \mathrm{~min}$, four $3 \mathrm{~min}$, and nine $6 \mathrm{~min}$ frames). The scanning period of $69 \mathrm{~min}$ was chosen as the low residual activity of $\left[{ }^{11} \mathrm{C}\right]$ carfentanil at subsequent acquisition frames would have resulted in a low signal-to-noise ratio. This particularly applies to occupancy studies in which the tissue concentration of tracer ligand is low. A transmission scan employing two extracorporeal ${ }^{68} \mathrm{Ge}$ rod sources was performed prior to each dynamic scan to correct for photon attenuation caused by subject's own tissues. At least $10 \times 10^{6}$ counts/slice was collected. For anatomical reference, a $1.5 \mathrm{~T}$ MRI scan (GE Signa, General Electric Medical Systems, Milwaukee, WI, USA) of the brain was acquired from the subjects participating in PET studies. The MRIs were acquired with a fast spoiled gradient echo sequence (repetition time, $11.3 \mathrm{~ms}$; echo time, $4.2 \mathrm{~ms}$; flip angle, $20^{\circ}$; matrix, $256 \times 256$; one acquisition), which resulted in 124 1.2-mm-thick axial images with no interslice gaps.

In regional analysis, integrated images of each of the three dynamic PET scans were realigned, and the obtained mean PET image was coregistered with the MRI for each subject. All realignment and coregistration procedures were performed using Statistical Parametric Mapping software version 99 (SPM99, Wellcome Department of Cognitive Neurology, University College London, England) and Matlab 6.5 for Windows (Math Works, Natick, MA, USA). The regions of interest (ROIs) were manually drawn in the thalamus, caudate nucleus, and frontal cortex of the coregistered MRIs using the Imadeus software (version
1.0, Forima, Turku, Finland) for the calculation of regional time-tissue radioactivity concentration curves. The simplified reference tissue model (Lammertsma and Hume, 1996), shown to be insensitive to changes in blood flow (Endres et $a l, 2003)$, was applied in the derivation of $\mu$-opioid receptor binding potential (BP; denotes $k_{3} / k_{4}$ in this study (Slifstein and Laruelle, 2001)) values from the regional time-radioactivity concentration curves. The occipital cortex was used as the reference region (Endres et al, 2003). The reduction in the amount of $\mu$-opioid receptors available for $\left[{ }^{11} \mathrm{C}\right]$ carfentanil binding after nalmefene administration was calculated as the decrease in the BP of $\left[{ }^{11} \mathrm{C}\right]$ carfentanil upon nalmefene treatment $\left(\mathrm{BP}^{\text {Nalmefene }}\right)$ in comparison with pre-drug baseline level ( $\left.\mathrm{BP}^{\text {Baseline }}\right)$ according to Equation 1.

$$
\text { Nalmefene occupancy }(\%)=\left(1-\frac{\mathrm{BP}^{\text {Nalmefene }}}{\mathrm{BP}^{\text {Baseline }}}\right) \times 100
$$

To visualize the distribution of $\mathrm{BP}$ values and $\mu$-opioid receptor occupancy by nalmefene, a voxel-based image analysis of the data was performed. Parametric images for the whole brain were calculated using the Matlab 6.5 and Receptor Parametric Mapping software (Gunn et al, 1997), based on the simplified reference tissue model (Lammertsma and Hume, 1996). Realignment and spatial normalization of BP images were made using the SPM99 to enable presentation of the results in the common stereotactic space.

\section{Statistical Analysis}

Pharmacokinetic parameters $\left(\mathrm{AUC}_{\tau, \infty}, C_{\max }\right)$ were analyzed using repeated measures analysis of variance. Natural logarithm transformation was used for these variables in order to achieve normality, if needed. $\mathrm{AUC}_{\tau}$ for repeated dosing was compared to the $\mathrm{AUC}_{\infty}$ of single dosing. No additional covariates were used in the statistical model. Time to peak concentration $\left(t_{\max }\right)$ of each period was analyzed using a Wilcoxon signed-ranks test. Terminal halflife $\left(t_{1 / 2}\right)$ was analyzed using repeated measures analysis of variance or Wilcoxon signed-ranks test, depending on the distribution. The limit of statistical significance for all analyses was set at $p<0.05$, and $90 \%$ confidence intervals for the ratios of geometric means (repeated dosing/single dose) were calculated. Occupancy and safety variables were analyzed by descriptive statistics. Statistical analyses were performed with the SAS for Windows version 8.2 (SAS Institute Inc., Cary, NC, USA).

\section{RESULTS}

All the enrolled subjects completed the study protocol. No clinically significant abnormalities or changes in the ECG recordings or QTc intervals were observed. Six subjects $(50 \%)$ reported at least one adverse event after singe nalmefene dose, and all 12 subjects (100\%) during the repeated dosing study period. The most common adverse events were restless legs (nine subjects), fatigue (eight subjects) and dizziness (five subjects). 


\section{Pharmacokinetics}

Nalmefene was rapidly absorbed with median $t_{\max }$ being $0.75 \mathrm{~h}$ after single dose and $0.98 \mathrm{~h}$ following the repeated dosing period. Nalmefene $C_{\max }$ was significantly $(p=0.048)$ higher after repeated dosing (mean $=28.51 \mathrm{ng} / \mathrm{ml}$, $\mathrm{SD}=10.04)$ compared to single dose (mean $=21.94 \mathrm{ng} / \mathrm{ml}$, $\mathrm{SD}=10.02$ ). The pharmacokinetic parameters of nalmefene are summarized in Table 1. Nalmefene plasma concentration showed quite similar exponential decline in the study periods. Individual plots of the plasma concentration-time data for intact and glucuronidated nalmefene are shown in Figure 1. During the repeated dosing period, mean trough concentrations of nalmefene rose from $2.14 \mathrm{ng} / \mathrm{ml}$ $(\mathrm{SD}=0.71)$ on day 2 to $2.80 \mathrm{ng} / \mathrm{ml}(\mathrm{SD}=0.96)$ on day 7 $(p=0.002)$. Steady-state was rapidly achieved as determined by visual inspection, and there was no statistically significant difference for plasma nalmefene concentrations between days 6 and $7(p=0.416)$. The terminal half-life of nalmefene following single and repeated dosing was $13.40 \mathrm{~h}$ $(\mathrm{SD}=3.13)$ and $13.38 \mathrm{~h}(\mathrm{SD}=1.63)$, respectively. There was no statistically significant difference $(p=0.270)$ between $\mathrm{AUC}_{\infty}($ mean $=144.8 \mathrm{ng} / \mathrm{ml} \times \mathrm{h}, \mathrm{SD}=28.6)$ of single dose and $\mathrm{AUC}_{\tau}($ mean $=136.5 \mathrm{ng} / \mathrm{ml} \times \mathrm{h}, \mathrm{SD}=31.6)$ of repeated dosing.

The pharmacokinetic parameters of nalmefene metabolites are given in Table 1. The plasma concentrations of nornalmefene, nalmefene glucuronide, and nornalmefene glucuronide increased rapidly after single and repeated dosing. Visual inspection of the trough concentration data revealed that steady-state was attained for all the metabolites. Maximum concentration of each nalmefene metabolite was significantly higher after repeated dosing than after single dose. Owing to the relatively low levels of analyte and small number of time points during the elimination phase, $t_{1 / 2}$ estimates for nornalmefene were highly inaccurate, and only values for repeated dosing are presented in Table 1 .

\section{PET Imaging}

Very high $\mu$-opioid receptor occupancy by nalmefene was detected $3 \mathrm{~h}$ after treatments, at which time point the occupancy was $100.0 \%$ after single dose and $87.2-100.0 \%$ after repeated dosing. Individual $\left[{ }^{11} \mathrm{C}\right]$ carfentanil BP values and the derived nalmefene occupancy values in the selected brain areas at each time point are presented in Table 2 and Table 3, respectively. Receptor occupancies declined in a rather similar rate in the selected three brain regions. At $74 \mathrm{~h}$ post nalmefene administration, occupancies were $12.1-31.6 \%$ after single dose and $13.0-45.8 \%$ after repeated treatment. Figure 2 shows individual $\mu$-opioid receptor occupancy-time plots of nalmefene in the thalamus, and the time courses of average nalmefene plasma concentration after the dosings. An average $\left[{ }^{11} \mathrm{C}\right]$ carfentanil BP image of two subjects at baseline and at $50 \mathrm{~h}$ after single nalmefene

Table I Summary of Pharmacokinetic Parameters for Nalmefene and Main Metabolites after Single and 7-Day Repeated Oral Dosing of Nalmefene $\mathrm{HCl}(20 \mathrm{mg})$ in 12 Subjects

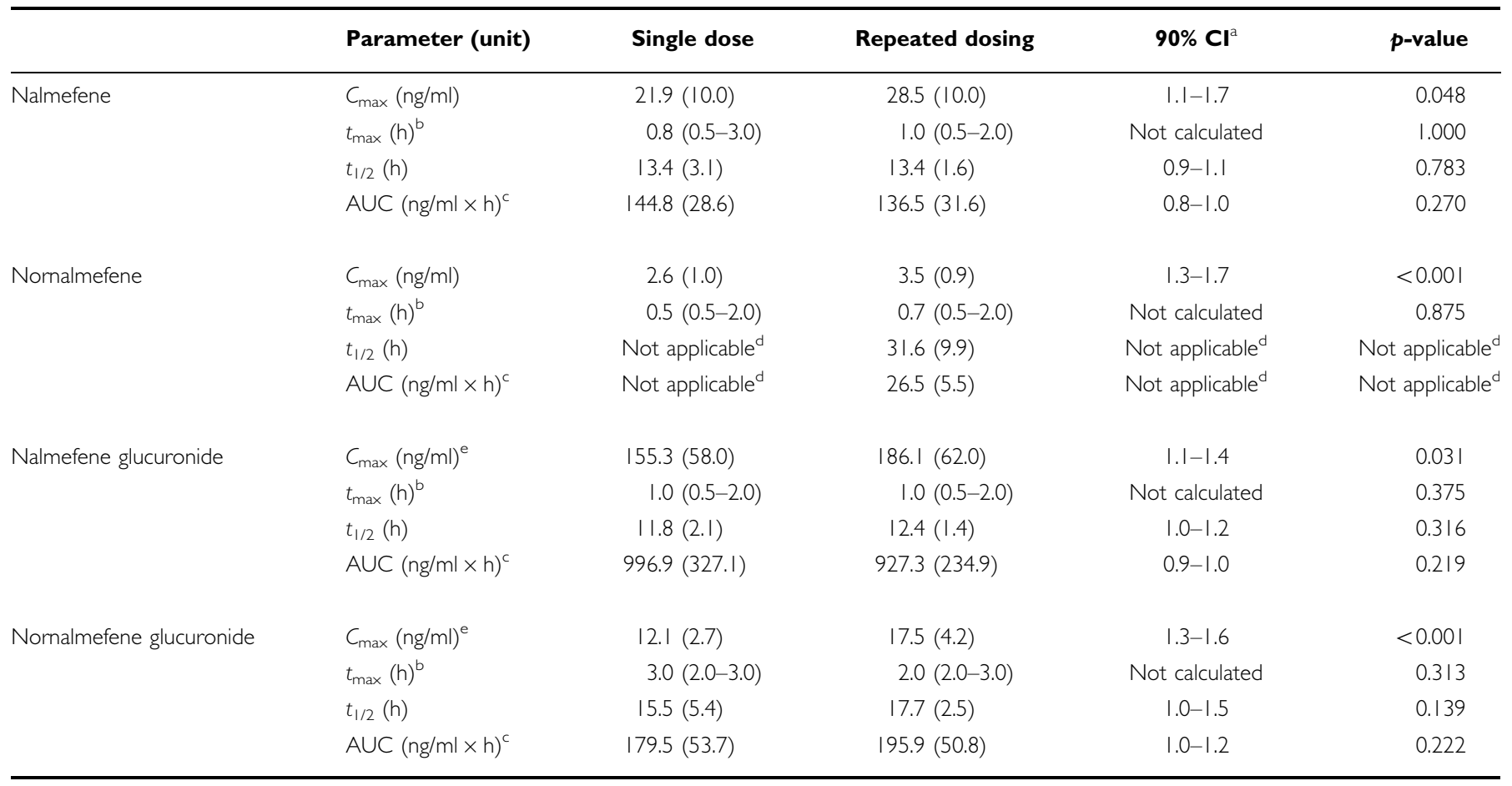

The table shows mean values \pm SD except for as noted below

${ }^{a}$ Ratio of geometric means: repeated dosing/single dose.

bMedian (range).

${ }^{c} \mathrm{AUC} \mathrm{C}_{\infty}$ for single dose, $A \cup C_{\tau}$ for repeated dosing.

${ }^{d} t_{1 / 2}$ after single dose highly inaccurate and therefore not given.

${ }^{e}$ Concentrations are expressed as $\mathrm{ng} / \mathrm{ml}$ of nalmefene and nornalmefene, respectively. 

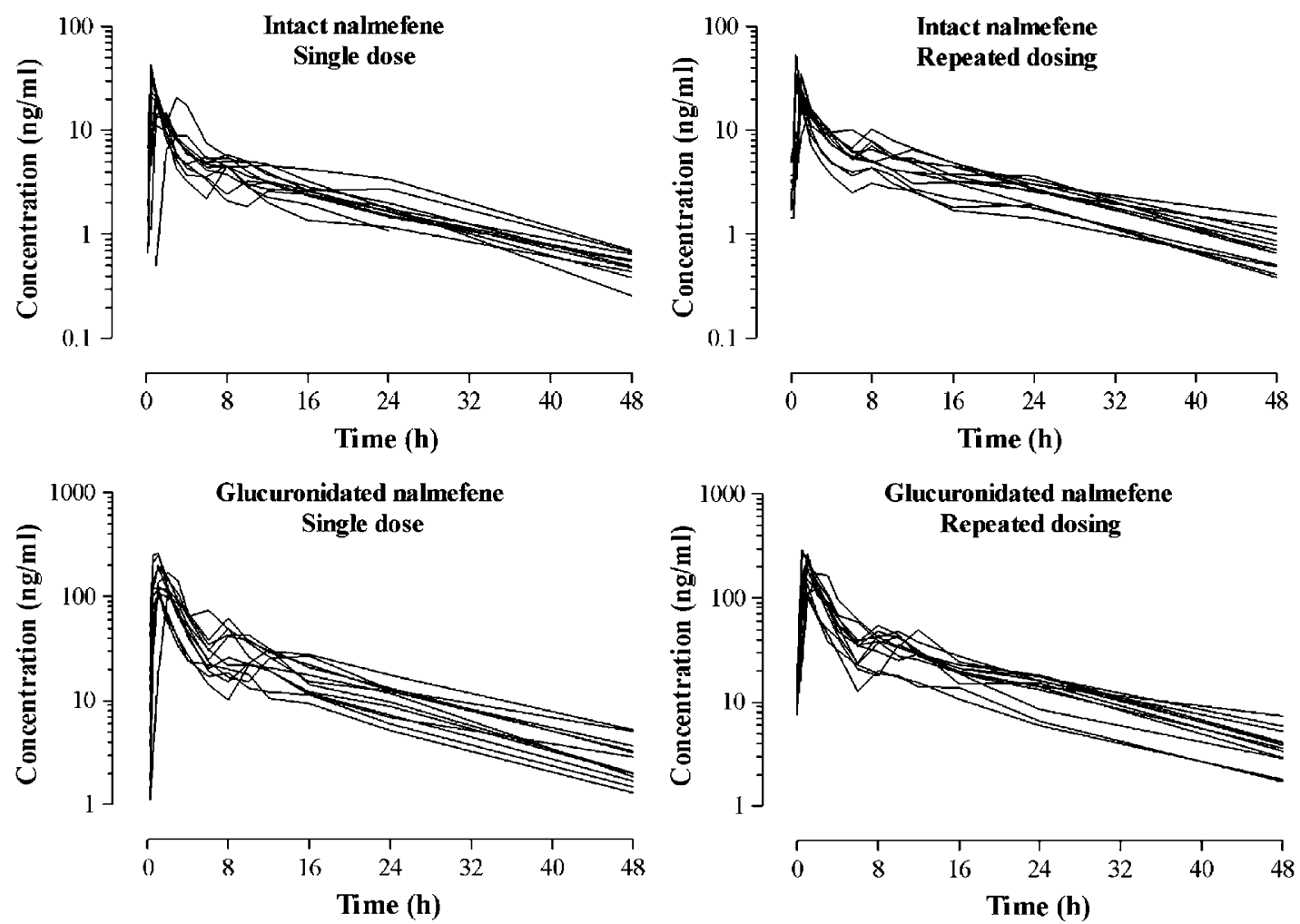

Figure I Individual plasma concentration-time data plots of intact (nonconjugated) and glucuronidated nalmefene following single and repeated oral nalmefene $\mathrm{HCl}(20 \mathrm{mg})$ administration in 12 subjects.

Table 2 Individual Binding Potential Values of $\left[{ }^{1}\right.$ C $]$ carfentanil at Selected Time Points (h) After Single and Repeated Nalmefene Dosing

Thalamus

\begin{tabular}{|c|c|c|c|c|c|c|}
\hline \multirow[b]{2}{*}{ Time } & \multicolumn{2}{|c|}{ 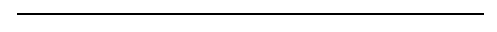 } & & \\
\hline & Single dose & Repeated dosing & Single dose & Repeated dosing & Single dose & Repeated dosing \\
\hline$B L$ & $2.28,2.57$ & $2.28,2.57$ & $1.43,1.55$ & $1.43,1.55$ & $0.80,0.94$ & $0.80,0.94$ \\
\hline 3 & $0.00,0.00$ & $0.00,0.33$ & $0.00,0.00$ & $0.00,0.00$ & $0.00,0.00$ & $0.00,0.00$ \\
\hline$B L$ & $2.72,2.66$ & $2.72,2.66$ & $1.22,1.47$ & $1.22,1.47$ & $0.98,0.87$ & $0.98,0.87$ \\
\hline 26 & $0.36,0.46$ & $0.32,0.37$ & $0.00,0.24$ & $0.00,0.17$ & $0.04,0.13$ & $0.00,0.10$ \\
\hline$B L$ & $2.72,2.19$ & 2.19 & $2.01,1.54$ & 1.54 & $1.00,0.90$ & 0.90 \\
\hline 74 & $1.49,1.92$ & $1.27,1.94$ & $0.91,1.04$ & $0.74,0.93$ & $0.57,0.58$ & $0.45,0.52$ \\
\hline
\end{tabular}

$\mathrm{N}=2$ at each time point except for $\mathrm{n}=1$ at $50 \mathrm{~h}$ after repeated treatment. Corresponding individual baseline (BL) binding potential value is given on the line above each value.

Table 3 Individual Values of Nalmefene Occupancy (\%) at $\mu$-Opioid Receptors at Selected Time Points (h) after Single and Repeated Dosing

\begin{tabular}{|c|c|c|c|c|c|c|}
\hline \multirow[b]{2}{*}{ Time } & \multicolumn{2}{|c|}{ Thalamus } & \multicolumn{2}{|c|}{ Caudate nucleus } & \multicolumn{2}{|c|}{ Frontal cortex } \\
\hline & Single dose & Repeated dosing & Single dose & Repeated dosing & Single dose & Repeated dosing \\
\hline 26 & $82.7,86.8$ & $86.1,88.2$ & $83.7,100.0$ & $88.4,100.0$ & $85.1,95.9$ & $88.5,100.0$ \\
\hline 50 & $48.4,64.3$ & 55.7 & $49.4,69.2$ & 64.3 & $52.2,72.0$ & 62.2 \\
\hline
\end{tabular}

$\mathrm{N}=2$ at each time point except for $n=1$ at $50 \mathrm{~h}$ after repeated treatment. 


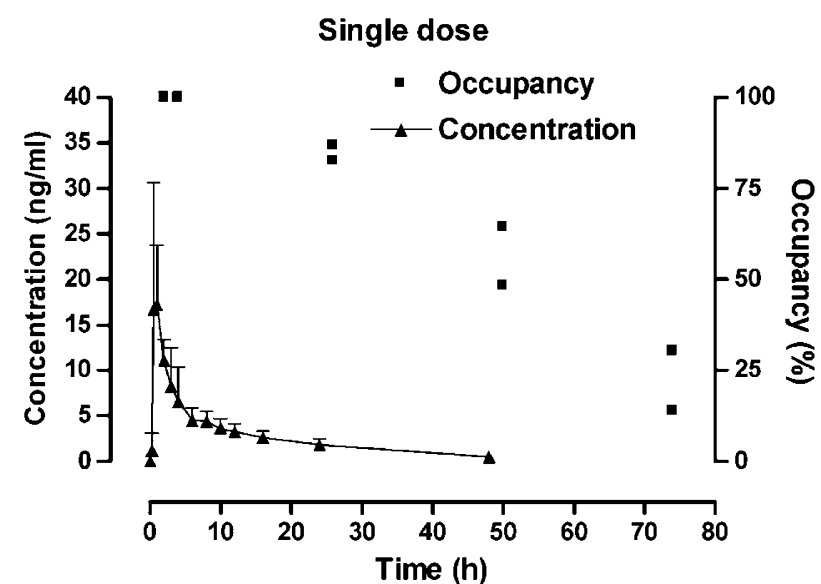

illustrated in Figure 3.

\section{DISCUSSION}

The present results suggest slow dissociation of nalmefene from $\mu$-opioid receptors in vivo in man and are in line with the findings that nalmefene exhibits sustained clinical antagonistic action of opioid effects in the brain (Gal et al, 1986). The slow dissociation rate and high occupancy level at $\mu$-opioid receptors render nalmefene a useful drug in the reversal of opioid effects in various clinical settings (Kim et al, 1997; Mason et al, 1999).

Consistent with the findings of a previous study (Dixon et al, 1987), oral nalmefene was rapidly absorbed, and its elimination half-life was $13.4 \mathrm{~h}$ after single and repeated dosing. Following the administration of nalmefene once per day over seven consecutive days, steady-state was attained by the third treatment day, and the data indicate linear pharmacokinetics. Pharmacokinetics of three nalmefene metabolites were determined. The highest concentration was detected for nalmefene glucuronide $1 \mathrm{~h}$ after the last dose of repeated nalmefene treatment; the peak concentration was 6.5 times higher than the $C_{\max }$ of the parent compound. Apparent steady-state was reached for all the metabolites. The ability of the nalmefene metabolites to permeate the blood-brain barrier and enter brain tissue has not been studied, but receptor binding studies with $\mu$ opioid receptors in guinea pig brain membranes have shown 1110- and 26-fold greater affinity for nalmefene than for nalmefene glucuronide or nornalmefene, respectively (Biotie Therapies Corp., data on file). The role of nalmefene metabolites in occupying $\mu$-opioid receptors after given nalmefene dosings can therefore be considered insignificant.

Both single and repeated nalmefene dosing led to a very high occupancy of $\mu$-opioid receptors in all brain areas examined; the thalamus, caudate nucleus, and frontal cortex. These brain areas have been shown to possess sufficient specific $\left[{ }^{11} \mathrm{C}\right]$ carfentanil binding for occupancy measurements (Endres et al, 2003), and they represent different $\mu$-opioid receptor densities in the brain (Dhawan et al, 1996). Depending on the brain area and dosing regimen, $\mu$-opioid receptor occupancy varied between 87.2 and $100.0 \% 3 \mathrm{~h}$ after dosing, at which time point nalmefene plasma concentration was already descending. The subsequent decline in the $\mu$-opioid receptor occupancy was similar after single and repeated nalmefene dosing, but clearly slower than the decline in the nalmefene plasma concentration. At $50 \mathrm{~h}$ after single or repeated nalmefene administration, occupancy was still $48.4-72.0 \%$, while nalmefene plasma concentration was negligible. Thereafter, nalmefene occupancy at $\mu$-opioid receptors declined at a faster rate, but a significant $\mu$-opioid receptor occupancy (up to $45.8 \%$ ) persisted at $74 \mathrm{~h}$ after the dosings. At $74 \mathrm{~h}$ after the nalmefene dosings, nalmefene plasma concentration was below the quantification limit. The most plausible explanation for the observed divergence of nalmefene plasma and brain clearance is a slow dissociation rate of nalmefene from $\mu$-opioid receptors that is in line with the high $\mu$-opioid receptor affinity of nalmefene $\left(K_{\mathrm{i}}=0.13 \mathrm{nM}\right)$ 
(Emmerson et al, 1994). Comparable relation between high receptor affinity and slow dissociation rate from receptor has been shown with antipsychotic drugs and striatal dopamine $\mathrm{D}_{2}$ receptors (Kapur and Seeman, 2000; Seeman and Tallerico, 1999).

The prolonged $\mu$-opioid receptor occupancy by nalmefene is shown here regionally in the brain, after single and repeated dosing, using the 3D PET methodology. The regional analysis revealed a quite similar rate of reduction in nalmefene occupancy in the brain areas examined, including the caudate nucleus and frontal cortex, which have been implicated with alcohol drinking (Herz, 1997; Koob, 1992). These findings support and essentially extend the earlier ones that showed the prolonged $\mu$-opioid receptor occupancy of a single intravenous nalmefene bolus $(1 \mathrm{mg})$ applying a simple dual-detector positron emission radiation detector system and $\left[{ }^{11} \mathrm{C}\right]$ carfentanil (Kim et al, 1997); nalmefene had a clearance half-time of $28.7 \pm 5.9 \mathrm{~h}$ from central $\mu$-opioid receptors (Kim et al, 1997), and the nalmefene plasma elimination half-life was $8.30 \pm 0.34 \mathrm{~h}$ (Kim et al, 1997). These results cannot be directly compared with the present data since different nalmefene doses, administration routes, and calculation methods were used. Additionally, for the present study, nalmefene brain clearance half-time was not calculated because only one or two occupancy values were acquired at each time point, and only four time points were measured. The low number of study subjects at each time point precluding proper inferential statistics of the true nalmefene-related occupancy constitutes a limitation of the present study. However, visual inspection (Figure 2) suggests brain clearance half-time of approximately $28 \mathrm{~h}$ after both single and repeated nalmefene administration, which is in line with the previous results (Kim et al, 1997).

According to the present PET data, the minimum duration of wash-out period (1 week) between the treatment periods can be considered sufficient to ensure almost complete elimination of nalmefene from the brain before the initiation of the second study period. Conversely, the maximum duration of the wash-out period (1 month) was defined so as to minimize the possibility of genuine changes caused by time (eg seasonal variability).

In the present study, nalmefene occupancies were derived from the detected BPs of $\left[{ }^{11} \mathrm{C}\right]$ carfentanil, which were defined as $k_{3} / k_{4}$ (Slifstein and Laruelle, 2001) using the simplified reference tissue model (Lammertsma and Hume, 1996), and the occipital cortex was used as the reference tissue. Such reference tissue modelling has been shown to produce BP estimates in reasonable agreement with those yielded by the more accurate compartmental modelling with a blood input function (Endres et al, 2003). However, nonspecific binding causes negative bias in BP values, which is independent on the occupancy level, and was thus cancelled out in the occupancy measure.

The indirect quantification of nalmefene binding at $\mu$ opioid receptors in this study is based on an assumption that $\left[{ }^{11} \mathrm{C}\right]$ carfentanil competes with nalmefene for binding at the receptors (Hietala, 1999). In addition to $\mu$-opioid receptors, nalmefene has also substantial affinity for $\delta$ - and $\kappa$-opioid receptors (Culpepper-Morgan et al, 1995; Emmerson et al, 1994), but $\left[{ }^{11} \mathrm{C}\right]$ carfentanil is a highly $\mu$-opioid receptor-selective agonist tracer $\left(K_{\mathrm{i}}=0.024 \mathrm{nM}\right)($ Stahl et al,
1977; Subramanian et al, 2000). Hence, the binding competition at $\mu$-opioid receptors by these ligands might to some extent reflect the clinical situation, in which nalmefene competes with endogenous opioid peptides. It is, however, not known to what extent $\mu$-opioid receptors should be occupied by an antagonist to block the pharmacological effects of endogenous opioid peptides, but a potent synthetic $\mu$-opioid receptor agonist methadone has been suggested to be clinically effective in doses that result in a low $(<10 \%) \mu$-opioid receptor occupancy (Melichar et al, 2004). Thus, a very high (>90\%) $\mu$-opioid receptor occupancy might be a prerequisite for the successful treatment of alcoholic patients with an opioid antagonist.

Altered activity of $\mu$-opioid receptor-mediated neurotransmission has been suggested to be an essential neurobiological mechanism in the reinforcement of alcohol drinking and development of alcoholism (Cowen and Lawrence, 1999; Gianoulakis, 2004; Herz, 1997; Koob, 1992; Oswald and Wand, 2004). Further support for the importance of endogenous opioid system in alcoholism is given by a recent $\left[{ }^{11} \mathrm{C}\right]$ carfentanil PET study showing a negative correlation between $\mu$-opioid receptor binding and alcohol craving in the brain of recently abstinent alcoholics (Bencherif et al, 2004). These results, together with earlier findings (Sinclair, 1990; Volpicelli et al, 1995), suggest that opioid antagonists reduce alcohol consumption by antagonizing opioid activation-mediated alcohol reinforcement. Patients in early withdrawal have, however, been shown vulnerable to naltrexone-precipitated adverse effects (O'Malley et al, 2000), and it has been hypothesized that regularly used opioid antagonists might even increase craving in early alcohol withdrawal and abstinence (Bencherif et al, 2004). Consequently, the most feasible way of treatment might be to treat alcoholics with nalmefene only when needed before alcohol drinking.

The plasma pharmacokinetics of nalmefene together with the $\mu$-opioid receptor occupancy-time data obtained in this study confirm that a persistent $\mu$-opioid receptor blockade can be induced by a single nalmefene tablet and support the rational of administering nalmefene when needed before alcohol drinking. On the other hand, the present results suggest that when the drug is taken daily, a high $\mu$-opioid receptor occupancy can be maintained even at plasma trough concentrations.

\section{ACKNOWLEDGEMENTS}

Dr Juhakoski, Dr Kallio, and Dr Karhuvaara were employees of Biotie Therapies Corp. at the time of present study. Dr Scheinin holds a patent on the use of nalmefene in the treatment of alcoholism. None of the other authors has any financial or personal relationships with the study sponsor. The original study was sponsored by Biotie Therapies Corp., Turku, Finland. Dr Kimmo Ingman received a scholarship from the Finnish Foundation for Alcohol Studies.

\section{REFERENCES}

Anton RF, Pettinati H, Zweben A, Kranzler HR, Johnson B, Bohn MJ et al (2004). A multi-site dose ranging study of nalmefene in 
the treatment of alcohol dependence. J Clin Psychopharmacol 24: 421-428.

Balldin J, Berglund M, Borg S, Mansson M, Bendtsen P, Franck J et al (2003). A 6-month controlled naltrexone study: combined effect with cognitive behavioral therapy in outpatient treatment of alcohol dependence. Alcohol Clin Exp Res 27: 1142-1149.

Bencherif B, Wand GS, McCaul ME, Kim YK, Ilgin N, Dannals RF et al (2004). Mu-opioid receptor binding measured by [11C]carfentanil positron emission tomography is related to craving and mood in alcohol dependence. Biol Psychiatry 55: 255-262.

Ciccocioppo R, Martin-Fardon R, Weiss F (2002). Effect of selective blockade of $\mathrm{mu}_{1}$ or delta opioid receptors on reinstatement of alcohol-seeking behavior by drug-associated stimuli in rats. Neuropsychopharmacology 27: 391-399.

Committee for Proprietary Medicinal Products (CPMP) and Internation Conference on Harmonisation (ICH) (1995). Good Clinical Practice. CPMP/ICH/135/95.

Cowen MS, Lawrence AJ (1999). The role of opioid-dopamine interactions in the induction and maintenance of ethanol consumption. Prog Neuropsychopharmacol Biol Psychiatry 23: $1171-1212$.

Culpepper-Morgan JA, Holt PR, LaRoche D, Kreek MJ (1995). Orally administered opioid antagonists reverse both mu and kappa opioid agonist delay of gastrointestinal transit in the guinea pig. Life Sci 56: 1187-1192.

DeHaven-Hudkins DL, Brostrom PA, Allen JT, Lesko LJ, Ferkany JW, Kaplita PV et al (1990). Pharmacologic profile of NPC 168 (naltrexone phenyl oxime), a novel compound with activity at opioid receptors. Pharmacol Biochem Behav 37: 497-504.

Dhawan BN, Cesselin F, Raghubir R, Reisine T, Bradley PB, Portoghese PS et al (1996). International Union of Pharmacology. XII. Classification of opioid receptors. Pharmacol Rev 48: 567-592.

Dixon R, Gentile J, Hsu HB, Hsiao J, Howes J, Garg D et al (1987). Nalmefene: safety and kinetics after single and multiple oral doses of a new opioid antagonist. J Clin Pharmacol 27: 233-239.

Drobes DJ, Anton RF, Thomas SE, Voronin K (2004). Effects of naltrexone and nalmefene on subjective response to alcohol among non-treatment-seeking alcoholics and social drinkers. Alcohol Clin Exp Res 28: 1362-1370.

Emmerson PJ, Liu MR, Woods JH, Medzihradsky F (1994). Binding affinity and selectivity of opioids at mu, delta and kappa receptors in monkey brain membranes. J Pharmacol Exp Ther 271: $1630-1637$.

Endres CJ, Bencherif B, Hilton J, Madar I, Frost JJ (2003). Quantification of brain $\mu$-opioid receptors with [ $\left.{ }^{11} \mathrm{C}\right]$ carfentanil: reference-tissue methods. Nucl Med Biol, 2003 30: 177-186.

Gal TJ, DiFazio CA, Dixon R (1986). Prolonged blockade of opioid effect with oral nalmefene. Clin Pharmacol Ther 40: 537-542.

Gastpar M, Bonnet U, Boning J, Mann K, Schmidt LG, Soyka M et al (2002). Lack of efficacy of naltrexone in the prevention of alcohol relapse: results from a German multicenter study. J Clin Psychopharmacol 22: 592-598.

Gianoulakis C (2004). Endogenous opioids and addiction to alcohol and other drugs of abuse. Curr Top Med Chem 4: 39-50.

Gunn RN, Lammertsma AA, Hume SP, Cunningham VJ (1997). Parametric imaging of ligand-receptor binding in PET using a simplified reference region model. Neuroimage 6: 279-287.

Herz A (1997). Endogenous opioid system and alcohol addiction. Psychopharmacology 129: 99-111.

Hietala J (1999). Ligand-receptor interactions as studied by PET: implications for drug development. Ann Med 31: 438-443.

June HL, Cummings R, Eiler WJ II, Foster KL, McKay PF, Seyoum $\mathrm{R}$ et al (2004). Central opioid receptors differentially regulate the nalmefene-induced suppression of ethanol- and saccharinreinforced behaviors in alcohol-preferring (P) rats. Neuropsychopharmacology 29: 285-299.
June HL, Grey C, Warren-Reese C, Durr LF, Ricks-Cord A, Johnson A et al (1998). The opioid receptor antagonist nalmefene reduces responding maintained by ethanol presentation: preclinical studies in ethanol-preferring and outbred Wistar rats. Alcohol Clin Exp Res 22: 2174-2185.

Kapur S, Seeman P (2000). Antipsychotic agents differ in how fast they come off the dopamine $\mathrm{D}_{2}$ receptors. Implications for atypical antipsychotic action. J Psychiatry Neurosci 25: 161-166.

Kim S, Wagner Jr HN, Villemagne VL, Kao PF, Dannals RF, Ravert HT et al (1997). Longer occupancy of opioid receptors by nalmefene compared to naloxone as measured in vivo by a dualdetector system. J Nucl Med 38: 1726-1731.

Koob GF (1992). Drugs of abuse: anatomy, pharmacology and function of reward pathways. Trends Pharmacol Sci 13: 177-184.

Kranzler HR, Modesto-Lowe V, Van Kirk J (2000). Naltrexone vs nefazodone for treatment of alcohol dependence. A placebocontrolled trial. Neuropsychopharmacology 22: 493-503.

Krystal JH, Cramer JA, Krol WF, Kirk GF, Rosenheck RA (2001). Naltrexone in the treatment of alcohol dependence. $N$ Engl J Med 345: 1734-1739.

Lammertsma AA, Hume SP (1996). Simplified reference tissue model for PET receptor studies. Neuroimage 4: 153-158.

Mason BJ, Ritvo EC, Morgan RO, Salvato FR, Goldberg G, Welch B et al (1994). A double-blind, placebo-controlled pilot study to evaluate the efficacy and safety of oral nalmefene $\mathrm{HCl}$ for alcohol dependence. Alcohol Clin Exp Res 18: 1162-1167.

Mason BJ, Salvato FR, Williams LD, Ritvo EC, Cutler RB (1999). A double-blind, placebo-controlled study of oral nalmefene for alcohol dependence. Arch Gen Psychiatry 56: 719-724.

Melichar JK, Hume SP, Williams TM, Daglish MR, Taylor LG, Ahmad $\mathrm{R}$ et al (2004). Using $\left[{ }^{11} \mathrm{C}\right]$-Diprenorphine to image opioid receptor occupancy by methadone in opioid addiction: clinical and preclinical studies. J Pharmacol Exp Ther 312: 309-315.

Meyer MC, Straughn AB, Lo MW, Schary WL, Whitney CC (1984). Bioequivalence, dose-proportionality, and pharmacokinetics of naltrexone after oral administration. J Clin Psychiatry 45: 15-19.

O'Malley SS (1995). Integration of opioid antagonists and psychosocial therapy in the treatment of narcotic and alcohol dependence. J Clin Psychiatry 56(Suppl 7): 30-38.

O’Malley SS, Krishnan-Sarin S, Farren C, O’Connor PG (2000). Naltrexone-induced nausea in patients treated for alcohol dependence: clinical predictors and evidence for opioidmediated effects. J Clin Psychopharmacol 20: 69-76.

O’Malley SS, Rounsaville BJ, Farren C, Namkoong K, Wu R, Robinson $\mathrm{J}$ et al (2003). Initial and maintenance naltrexone treatment for alcohol dependence using primary care $v s$ specialty care: a nested sequence of 3 randomized trials. Arch Intern Med 163: 1695-1704.

Oncken C, Van Kirk J, Kranzler HR (2001). Adverse effects of oral naltrexone: analysis of data from two clinical trials. Psychopharmacology (Berl) 154: 397-402.

Oswald LM, Wand GS (2004). Opioids and alcoholism. Physiol Behav 81: 339-358.

Seeman P, Tallerico T (1999). Rapid release of antipsychotic drugs from dopamine $\mathrm{D}_{2}$ receptors: an explanation for low receptor occupancy and early clinical relapse upon withdrawal of clozapine or quetiapine. Am J Psychiatry 156: 876-884.

Sinclair JD (1990). Drugs to decrease alcohol drinking. Ann Med 22: 357-362.

Slifstein M, Laruelle M (2001). Models and methods for derivation of in vivo neuroreceptor parameters with PET and SPECT reversible radiotracers. Nucl Med Biol 28: 595-608.

Srisurapanont M, Jarusuraisin N (2002). Opioid antagonists for alcohol dependence. Cochrane Database Syst Rev 2: CD001867.

Stahl KD, van Bever W, Janssen P, Simon EJ (1977). Receptor affinity and pharmacological potency of a series of narcotic 
analgesic, anti-diarrheal and neuroleptic drugs. Eur J Pharmacol 46: 199-205.

Subramanian G, Paterlini MG, Portoghese PS, Ferguson DM (2000). Molecular docking reveals a novel binding site model for fentanyl at the $\mu$-opioid receptor. J Med Chem 43: 381-391.
Volpicelli JR, Watson NT, King AC, Sherman CE, O'Brien CP (1995). Effect of naltrexone on alcohol 'high' in alcoholics. Am J Psychiatry 152: 613-615.

World Medical Association Declaration of Helsinki. Ethical principles for medical research involving human subjects (2000). JAMA 284: 3043-3045. 